Chen, C. W.-y. (2021). I participate, therefore I am: A study on students' efforts of helping Google Translate to refine its translation results. Current Trends in Teaching and Learning Translation E, 8, 449 - 482. https://doi.org/10.51287/cttle2021516

\title{
I PARTICIPATE, THEREFORE I AM: A STUDY ON STUDENTS' EFFORTS OF HELPING GOOGLE TRANSLATE TO REFINE ITS TRANSLATION RESULTS
}

Cheryl Wei-yu Chen

National Taipei University of Business

\section{Abstract}

This study invited a group of Taiwanese English-as-a-foreignlanguage (EFL) tertiary-level students to help Google Translate (GT) Community to refine its translation output. The participants engaged in 5 types of translation refinement tasks by responding to the input provided by GT Community (the first four tasks) or entering translation suggestions when encountering inappropriate translation generated by GT (the fifth task). The results indicated that the participants were able to generate highly accurate output for the first four tasks. With regard to the fifth task, many students entered proverbs, idioms, cultural expressions or slang for GT to translate and deemed GT's inability to translate beyond literal meaning as something to be improved upon. There were also nearly $25 \%$ of over-correction due to students' excessive scrutiny. 
Chen, C. W.-y. (2021). I participate, therefore I am: A study on students' efforts of helping Google Translate to refine its translation results. Current Trends in Teaching and Learning Translation E, 8, 449 - 482. https://doi.org/10.51287/cttle2021516

All in all, students generally enjoyed the experience of helping GT to improve its translation quality. As students took the role of active contributors of knowledge, they developed competence and gained experience of participating in the digital world. Their participation also helped them to refine their language knowledge and developed their research abilities. The current study ends with a few possible directions for future research.

Keywords: Google Translate (GT), Google Translate Community, translation refinement tasks, online participation

\section{INTRODUCTION}

Research on the use of free online machine translation (FOMT) tools in pedagogical settings has exploded with the growing popularity of Google Translate (GT). One strand of such research has debated the threats these devices can pose on academic honesty (Case, 2015; Correa, 2014; Ducar \& Schocket, 2018; Groves \& Mundt, 2015; Hutchins, 2001; Mundt \& Groves, 2016; Niño et al., 2014; Somers et al., 2006). In this line of research, FOMT tools are seen as capable of providing disruptions to language learning activities (Case, 2015). GT has also been described as "an inescapable reality" that language teachers need to "make peace with" (Ducar \& Schocket, 2018, p. 779) while others use analogies such as "a double-edged sword" (Mundt \& 
Chen, C. W.-y. (2021). I participate, therefore I am: A study on students' efforts of helping Google Translate to refine its translation results. Current Trends in Teaching and Learning Translation E, 8, 449 - 482. https://doi.org/10.51287/cttle2021516

Groves, 2016) or "friend or foe" (Groves \& Mundt, 2015) to discuss their ambivalence towards the pedagogical use of GT. The second strand of FOMT research employed GT and other FOMT tools in teaching learners how to write in a second language (Enkin \& MejíasBikandi, 2016; Garcia \& Pena, 2011; Jiménez-Crespo, 2017; Lee, 2019; Niño, 2007; Tsai, 2019; Yamada, 2015). These studies typically involved using some type of FOMT-produced output (e.g., correcting raw GT output to obtain an acceptable text), and FOMT was generally perceived as beneficial for providing students with assistance in the translation process. While many language learners seem to perceive some value in FOMT (Briggs, 2018; Niño 2009), they have reported having limited trust in FOMT's output accuracy. Moreover, Briggs (2018) found that his Korean students generally lacked the ability to detect obvious errors from FOMT output. This lack of ability should be a concern for language teachers because it prevents learners from effectively using FOMT tools in their language learning process (Briggs, 2018).

Instead of gauging students' perceived usefulness of FOMT tools, the current study invited a group of Taiwanese English-as-a-foreignlanguage (EFL) tertiary-level students to help GT Community to refine its translation output. By becoming active contributors in GT Community, students could develop their analytical skills and awareness of using GT effectively and appropriately. They also received 
Chen, C. W.-y. (2021). I participate, therefore I am: A study on students' efforts of helping Google Translate to refine its translation results. Current Trends in Teaching and Learning Translation E, 8, 449 - 482. https://doi.org/10.51287/cttle2021516

teacher feedback on the accuracy of their inputs to the GT Community to help them detect possible gaps in their language knowledge. This study was guided by the following research questions:

(1) How accurate were students in generating translation suggestions for Google Translate Community?

(2) How did students perceive the experience of helping Google Translate to refine its translation output?

\section{LITERATURE REVIEW}

\subsection{Theoretical Framework: Participatory Culture}

The current study is guided by Jenkins' participatory culture (2006). In a participatory culture, members play the role of both consumers and prosumers to actively create and disseminate content. Through collaboration and networking, "[c]onsumption becomes production; reading becomes writing; spectator culture becomes participatory culture" (Jenkins, 2006, p. 60). Members of a participatory culture also believe that their contribution matters (Jenkins et al., 2006) and they often work together to solve problems and develop new knowledge. It is a world which values collective intelligence (Levy, 2000), where likeminded individuals work together to pool their collective knowledge towards a common goal. Levy (2000) argues that in such a world, 
Chen, C. W.-y. (2021). I participate, therefore I am: A study on students' efforts of helping Google Translate to refine its translation results. Current Trends in Teaching and Learning Translation E, 8, 449 - 482. https://doi.org/10.51287/cttle2021516

nobody knows everything, but everyone knows something. The process of building these knowledge communities is also the driving force behind knowledge refinement and social development (Levy, 2000). Online message boards and Wikipedia are two prime examples of such knowledge communities made possible by the concept of participatory culture.

The concept of participatory culture is most often used to describe the production of some type of published media such as YouTube videos (Chau, 2010). Nonetheless, we create new contents not just to entertain, but also to learn and expand our mental capacities (Jenkins et al., 2006). Joining a knowledge-based community such as Google Translate Community therefore adheres to the spirit of participatory culture. By taking a critical stance towards the reliability of GT output, students can practice to discriminate between accurate and inaccurate information. According to Choi and her colleagues (Choi et al., 2017), taking such a stance is an important condition to become a responsible citizen in the digital age. Instead of just using GT as passive consumers, the participants of this study took the role of feedback providers to help GT refine its translation quality. It is hoped that this experience will allow students to see how they can contribute in a participatory culture.

\subsection{Google Translate Community and Other Similar Initiatives}


Chen, C. W.-y. (2021). I participate, therefore I am: A study on students' efforts of helping Google Translate to refine its translation results. Current Trends in Teaching and Learning Translation E, 8, 449 - 482. https://doi.org/10.51287/cttle2021516

Google first launched its GT Community in 2014 to invite volunteers to help improve the services of Google Translate. At the time of initiating the study (as of July, 2020), the English-to-Chinese Google Translate Community (https://translate.google.com/contribute ; see Figure 1 for the log-in page) invited its members to help with the following types of translation refinement work:

(1) Contents related to COVID-19: By clicking the left-hand-side box under the COVID-19 section, a volunteer will see an English text and its Chinese translation, and he/she has to decide whether the Chinese translation is appropriate. If the volunteer clicks the other box under the same section, he/she will see an untranslated English text which needs to be translated into Chinese by members of the GT Community.

(2) Confirmation: In this section, a volunteer will see a "generaltopic" English text and its Chinese translation. He/She will then decide whether the translation is accurate by clicking "Like" or "Dislike."

(3) Translation: A volunteer will see a string of English words or some English sentences. He/She has to type in the correct Chinese translation.

Besides these three sections, GT users can also help GT to refine its translation accuracy if they encounter incorrect translation output when 
Chen, C. W.-y. (2021). I participate, therefore I am: A study on students' efforts of helping Google Translate to refine its translation results. Current Trends in Teaching and Learning Translation E, 8, 449 - 482. https://doi.org/10.51287/cttle2021516

using GT. They can simply click the "Provide feedback" button (see Figure 1) and enter the correct translation.

To sum up, the participants engaged in 5 types of translation refinement tasks for the current study:

Task 1: English-to-Chinese translation confirmation (COVID-19 related contents and general contents)

Task 2: English-to-Chinese translation (COVID-19 related contents and general contents)

Task 3: Chinese-to-English translation confirmation (COVID-19 related contents and general contents)

Task 4: Chinese-to-English translation (COVID-19 related contents and general contents)

Task 5: Write comments to GT on inappropriate translation from their daily use of GT

For Tasks (1) and (3), students would see both the source text and its translation on the screen, and they had to press either "Like" or "Dislike" button to verify whether they have the same meaning; if they could not decide on the translation quality, they could also press "Skip" and move on to the next input. For Tasks (2) and (4), they read the source text, typed in its translation, and then pressed "Submit" to turn in the translation result to GT. For Task (5), students did not have to verify 
Chen, C. W.-y. (2021). I participate, therefore I am: A study on students' efforts of helping Google Translate to refine its translation results. Current Trends in Teaching and Learning Translation E, 8, 449 - 482. https://doi.org/10.51287/cttle2021516

or translate any text supplied by GT Community. Instead, in their daily use of GT, they might encounter inappropriate translation. They could supply GT with appropriate translation and write some brief explanations to help GT refine its translation output.

Figure 1: Log-in page of the Chinese version of Google Translate Community (as of July, 2020)
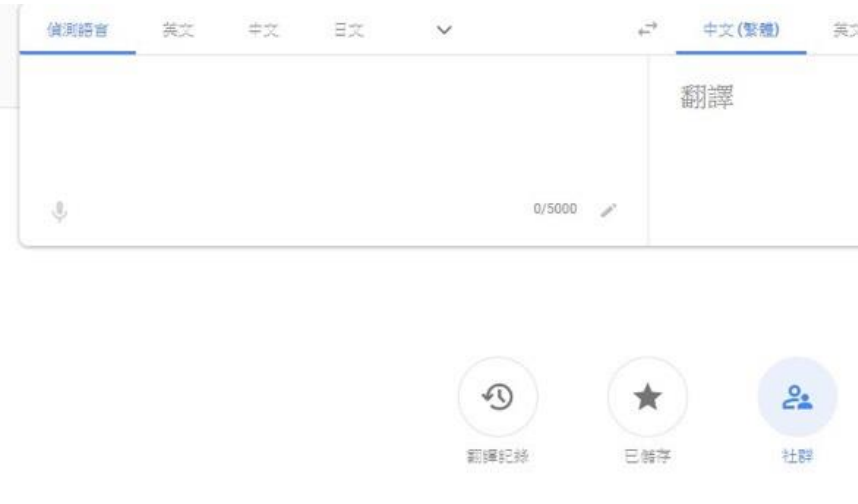
Chen, C. W.-y. (2021). I participate, therefore I am: A study on students' efforts of helping Google Translate to refine its translation results. Current Trends in Teaching and Learning Translation E, 8, 449 - 482. https://doi.org/10.51287/cttle2021516

GT Community is not the only knowledge-based platform to summon volunteer translators around the world to help with its translation work. TED launched its translator program in 2009. Since then, more than 120,000 translations have been published in 116 languages, by more than 33,000 volunteer translators (https://www.ted.com/about/programsinitiatives/ted-translators). The most productive contributor is an Argentinian named Sebastian Betti (https://www.ted.com/profiles/228293/translator) who has helped translate and review nearly 6000 TED talks. In Taiwan, the leading English-learning video platform VoiceTube (https://tw.voicetube.com/) once relied on its many volunteer translators to provide subtitles for their online videos. In June, 2020, an announcement was made on the platform that beginning on June 22, 2020, VoiceTube would no longer recruit volunteer translators, as the company decided to switch to machine translation to translate its vast amount of audiovisual materials (https://tw.voicetube.com/translate/our_translators?ref=footer).

\section{RESEARCH DESIGN}

\subsection{The participants and Research Context}

The current study was situated in a one-year Freshman English writing course designed to help a group of Taiwanese EFL tertiary students improve their English writing skills. The class met for two hours every 
Chen, C. W.-y. (2021). I participate, therefore I am: A study on students' efforts of helping Google Translate to refine its translation results. Current Trends in Teaching and Learning Translation E, 8, 449 - 482. https://doi.org/10.51287/cttle2021516

week for two consecutive 18-week semesters. The primary teaching objective was to engage students to express their ideas clearly and critically. Attentions were paid to standard written English, sentence structure, and grammar usage. Students were also encouraged to judicially use technological tools (such as online dictionaries and GT) during their editing and revising process. This study took place in the first semester (i.e., the fall semester) of the course.

Twelve female and 1 male students $(\mathrm{N}=13)$ participated in this study. They were freshman English majors in a university in northern Taiwan. They all spoke Mandarin Chinese as their first language and had learned English as a foreign language since they were in kindergartens or elementary schools. According to their self-reported scores from standardized English exams, their general English proficiency levels ranged from $\mathrm{B} 1$ to $\mathrm{C} 1$ in the Common European Framework of Reference for Language (CEFR). During an informal class discussion in the first week of the course, most students remarked that they had used GT before but had not heard of GT Community. In other words, providing feedback for GT Community was a novel experience for all the participants.

\subsection{The GT Refinement Project}


Chen, C. W.-y. (2021). I participate, therefore I am: A study on students' efforts of helping Google Translate to refine its translation results. Current Trends in Teaching and Learning Translation E, 8, 449 - 482. https://doi.org/10.51287/cttle2021516

In the first class of the fall semester, the researcher who was also the course instructor debriefed students on the GT refinement project. The project was divided into two parts. The first part of the project involved Tasks 1 to 4 . Each student had to respond to a total of 20 translated results in Chinese and another 20 in English. Before they submitted their response to a prompt, they had to screen capture it; each screencaptured image would later be arranged in a Microsoft Word document to be submitted to the instructor.

For the second part of the project (Task 5), students had to provide 10 translation suggestions to GT as they spotted inappropriate translation output when they used GT in their daily lives. During the debriefing, an example supplied by the instructor was the Chinese translation of the word "digital" as in phrases like "digital contents" or "the digital age." GT translated the word as “數字的, ” meaning numerical in English. The instructor demonstrated how to supply GT with the correct input.

Students' GT refinement projects were collected in Week 10 of the semester which were then read meticulously by both the instructor and a professional freelance translator to rate the accuracy of the inputs of the first part of the projects. If the two raters judged an input differently, they would discuss its accuracy until consensus was reached. A questionnaire (Appendix) was administered to gauge students' perceptions of the GT project in Week 17 of the semester. 
Chen, C. W.-y. (2021). I participate, therefore I am: A study on students' efforts of helping Google Translate to refine its translation results. Current Trends in Teaching and Learning Translation E, 8, 449 - 482. https://doi.org/10.51287/cttle2021516

\subsection{Data Collection and Analysis}

The major data sources were students' GT refinement projects and questionnaires. As mentioned earlier, the participants of this study engaged in 5 types of translation refinement tasks for this study. The accuracy rates for the first 4 types will be presented in the next section, and the appropriateness of students' written inputs for Task 5 will also be discussed. In addition, students' questionnaire responses were read carefully to understand students' perceptions of helping GT to refine its translation output. Relevant themes will be presented in the next section.

\section{RESULTS}

\subsection{Research Question 1: Accuracy of Student-Generated Suggestions}

The results indicated that the participants were highly accurate when they were called upon to translate for GT Community and verify tentative translation results. Table 1 presents a summary of students' performance for the first four tasks.

Table 1: Summary of students' performance for Tasks 1-4 
Chen, C. W.-y. (2021). I participate, therefore I am: A study on students' efforts of helping Google Translate to refine its translation results. Current Trends in Teaching and Learning Translation E, 8, 449 - 482. https://doi.org/10.51287/cttle2021516

\begin{tabular}{|c|c|c|c|}
\hline Task & $\begin{array}{c}\text { Total } \\
\text { number of } \\
\text { inputs }\end{array}$ & $\begin{array}{c}\text { Number of } \\
\text { inaccurate } \\
\text { inputs }\end{array}$ & $\begin{array}{c}\text { Accuracy } \\
\text { rate }\end{array}$ \\
\hline $\begin{array}{c}\text { (1) English-to-Chinese } \\
\text { translation confirmation }\end{array}$ & 98 & 6 & $93.4 \%$ \\
\hline $\begin{array}{c}\text { (2) English-to-Chinese } \\
\text { translation }\end{array}$ & 145 & 7 & $95.2 \%$ \\
\hline $\begin{array}{c}\text { (3) Chinese-to-English } \\
\text { translation confirmation }\end{array}$ & 110 & 0 & $94.9 \%$ \\
\hline $\begin{array}{c}\text { (4) Chinese-to-English } \\
\text { translation }\end{array}$ & 138 & 7 & \\
\hline
\end{tabular}

Generally speaking, students were highly accurate when verifying GT's translation results (Tasks $1 \& 3$ ) and generating translation (Tasks $2 \&$ 4). Task 1 yielded the lowest accuracy rate among the four sets of results. The six erroneous instances of English-to-Chinese translation confirmation were produced by Students \#2 (who produced four instances), Student \#4 and Student \#9. Table 2 summarizes the original English texts (with original capitalization and punctuation) and their Chinese translation supplied by GT Community, students' decisions (whether they thought the Chinese translation was correct or not), and their reasons for the decisions (from my multiple email communications with them, January 16, 2021): 
Chen, C. W.-y. (2021). I participate, therefore I am: A study on students' efforts of helping Google Translate to refine its translation results. Current Trends in Teaching and Learning Translation E, 8, 449 - 482. https://doi.org/10.51287/cttle2021516

Table 2: The six erroneous instances of Task 1

\begin{tabular}{|c|c|c|c|}
\hline English Text & $\begin{array}{l}\text { Chinese } \\
\text { translatio } \\
\mathrm{n}\end{array}$ & $\begin{array}{l}\text { Student's } \\
\text { decision }\end{array}$ & Students' explanation \\
\hline $\begin{array}{l}\text { (1) loyalty is } \\
\text { less and less } \\
\text { about points } \\
\text { and } \\
\text { threshold. }\end{array}$ & $\begin{array}{l}\text { 忠誠是 } \\
\text { 關於點 } \\
\text { 和門檻 } \\
\text { 越來越 } \\
\text { 少. }\end{array}$ & Correct & $\begin{array}{l}\text { Student \#2: The word-by-word } \\
\text { translation looks right to me. }\end{array}$ \\
\hline $\begin{array}{l}\text { (2) If the } \\
\text { download } \\
\text { doesn't } \\
\text { begin } \\
\text { automaticall } \\
\text { y, click here } \\
\text { to retry. }\end{array}$ & $\begin{array}{l}\text { 如果下 } \\
\text { 載未自 } \\
\text { 動開 } \\
\text { 始, 請 } \\
\text { 點擊此 } \\
\text { 處重試. }\end{array}$ & Incorrect & $\begin{array}{l}\text { Student \#2: The second part of the } \\
\text { English sentence ("click here to } \\
\text { retry") does not have a subject. }\end{array}$ \\
\hline $\begin{array}{l}\text { (3) the awards } \\
\text { honored }\end{array}$ & $\begin{array}{l}\text { 該獎項 } \\
\text { 授予團 }\end{array}$ & Incorrect & $\begin{array}{l}\text { Student \#2: I didn't think the } \\
\text { Chinese translation was incorrect. }\end{array}$ \\
\hline
\end{tabular}


Chen, C. W.-y. (2021). I participate, therefore I am: A study on students' efforts of helping Google Translate to refine its translation results. Current Trends in Teaching and Learning Translation E, 8, 449 - 482. https://doi.org/10.51287/cttle2021516

\begin{tabular}{|c|c|c|c|}
\hline $\begin{array}{l}\text { groups and } \\
\text { charities that } \\
\text { helped } \\
\text { people } \\
\text { following } \\
\text { the } 2004 \\
\text { tsunami }\end{array}$ & $\begin{array}{l}\text { 體和慈 } \\
\text { 善機 } \\
\text { 構, 帛 } \\
\text { 助 } 2004 \\
\text { 年海嘯 } \\
\text { 之後的 } \\
\text { 人 }\end{array}$ & & $\begin{array}{l}\text { The first English word "the" was } \\
\text { not capitalized, and there was no } \\
\text { period to end the sentence. }\end{array}$ \\
\hline $\begin{array}{l}\text { (4) Pelagic } \\
\text { Elasmobranc } \\
\text { hs }\end{array}$ & $\begin{array}{l}\text { 遠洋軟 } \\
\text { 骨魚類 }\end{array}$ & Incorrect & $\begin{array}{l}\text { Student \#2: The English } \\
\text { translation I found was } \\
\text { "Pelagic cartilaginous fish." }\end{array}$ \\
\hline $\begin{array}{l}\text { (5) I did but I } \\
\text { didn't know } \\
\text { cfs give that } \\
\text { much } \\
\text { money:/ }\end{array}$ & $\begin{array}{l}\text { 我有, } \\
\text { 但我不 } \\
\text { 知道廣 } \\
\text { 告給那 } \\
\text { 麼多錢:/ }\end{array}$ & Incorrect & $\begin{array}{l}\text { Student \#4: From my Google } \\
\text { Search, I thought cfs stands for } \\
\text { "container freight station." }\end{array}$ \\
\hline $\begin{array}{l}\text { (6) Six } \\
\text { presumptive } \\
\text { positive } \\
\text { cases were } \\
\text { reported in } \\
\text { San } \\
\text { Francisco. }\end{array}$ & $\begin{array}{l}\text { 舊金山 } \\
\text { 報告了 } 6 \\
\text { 例疑似 } \\
\text { 陽性病 } \\
\text { 例。 }\end{array}$ & Incorrect & $\begin{array}{l}\text { Student \#6: I looked up } \\
\text { “presumptive" in the online } \\
\text { dictionary (Yahoo) and found that } \\
\text { it means “假定的、假設的。 } \\
\text { " Now I read the sentence again. } \\
\text { It is a correct sentence. }\end{array}$ \\
\hline
\end{tabular}


Chen, C. W.-y. (2021). I participate, therefore I am: A study on students' efforts of helping Google Translate to refine its translation results. Current Trends in Teaching and Learning Translation E, 8, 449 - 482. https://doi.org/10.51287/cttle2021516

Four of the 6 erroneous cases came from Student \#2. This student seemed to be lost in the English-to-Chinese translation confirmation task. She deemed (2), (3) and (4) from Table 2 incorrect due to the problems in the original English texts whereas she should have focused on whether the English texts were correctly translated into Chinese. On the other hand, the instances of (1), (5) and (6) seem to require more careful reading and translation experience from the students to be able to verify their accuracy.

The second task invited students to provide Chinese translation for English texts. The English prompts students received ranged from single words (e.g., "less" from Student \#8), short phrases (e.g., "Before eating food" from Student \#7) to full sentences (e.g., "On 31 December 2019, a cluster of pneumonia cases of unknown aetiology was reported in Wuhan, Hubei Province, China" from Student \#6). Some of the English prompts were written in ungrammatical or non-standard English (e.g., "thank you for teach!" from Student \#6). A careful analysis of the 7 incorrect Chinese translations revealed a careless mistake by Student \#10 who translated “soybean” as “豆漿” (soy milk) and an over interpretation of the phrase "no good" as in "I'm no good at this stuff” by Student \#11 who translated “no good” into “反感” in Chinese. The other five erroneous instances all contained technical terms from the medial (some related to Covid-19) and technological fields: 
Chen, C. W.-y. (2021). I participate, therefore I am: A study on students' efforts of helping Google Translate to refine its translation results. Current Trends in Teaching and Learning Translation E, 8, 449 - 482. https://doi.org/10.51287/cttle2021516

(7) To estimate baseline susceptibility to COVID-19 in the community and estimate both symptomatic and asymptomatic exposure rates in the population through seroprevalence monitoring (Student \#2)

(8) This might also guide or facilitate the search for the reservoir, intermediate and amplifying animal host(s) of SARS-CoV-s, with important implications in the prevention of future spillovers.

(Student \#2)

(9) Luke said nothing about the physical cause of Anania's sudden death. (Student \#8)

(10) This article incorporates text from a free content work. (Student \#12)

(11) Media related to Hand washing at Wikimedia Commons (Student \#13)

Written in complex structures, (7) and (8) were also loaded with medical terms which further impeded students' abilities to translate them correctly. The term "physical cause" in (9) was challenging for Student \#8, as she translated it into “身體因素” whereas the accurate translation should have been the more precise term “物理病因." Like Student\# 8, Students \#12 and \#13 also produced unprecise translations for "free content work" and "Wikimedia Commons"; both terms can be categorized as new terminology in the Web 2.0 age. As revealed by 
Chen, C. W.-y. (2021). I participate, therefore I am: A study on students' efforts of helping Google Translate to refine its translation results. Current Trends in Teaching and Learning Translation E, 8, 449 - 482. https://doi.org/10.51287/cttle2021516

students' questionnaires, these technical terms posed a great challenge for students to translate them accurately. They often had to check other sources to decide whether the GT input was correct or not.

With regard to the third task (Chinese-to-English translation confirmation), there was no error in students' confirmation. As for Task 4, a total of eight errors were identified. Besides a spelling error by Student \#11 (who spelt "own" as "won") and a careless mistake by Student \#8 (who translated “繁體” as “simplified”), the other 5 errors can be further classified into sentence-level errors and problems with word usage:

Sentence-level errors:

(12) *Can only participate once a month, test results/time will be included in the national ranking (Student \#1 for “一個月只能參加 一次，考試成績/時間將會列入全國總排名”)

(13) *Ruskin muttered to himself, he dared not speak loudly. (Student \#2 for “羅斯金喃喃自語道，他不敢大聲說話”)

Problems with word usage

(14) * Do you always hope there is a universal robot to handle all the debris in your life? (Student \#1 for the sentence “是不是總希望 生活中有一個萬能機器人來處理一切雜務呢?)

(15) * Sign-in Center (for “登錄中心” by Student \#9)

(16) * $\log$ in (for “進行” by Student \#11) 
Chen, C. W.-y. (2021). I participate, therefore I am: A study on students' efforts of helping Google Translate to refine its translation results. Current Trends in Teaching and Learning Translation E, 8, 449 - 482. https://doi.org/10.51287/cttle2021516

In (12), the main problem was a missing subject whereas (13) was a comma splice. In (14), (15) and (16), the English translations were not precise enough to convey the original texts in Chinese. In the case of (14), a more precise English word "omnipotent" or "all-powerful" should replace "universal" and "chores" for "debris."

Besides these 4 refinement tasks, students were also invited to provide 10 translation suggestions to GT when they spotted inappropriate translation output in their daily use of GT. An examination of students' input revealed that many original texts are proverbs ("Beauty is only skin deep"), idiomatic expressions ("green hand" as someone who is inexperienced), or cultural expressions or slang ("pineapple cake" as a common type of Taiwanese pastry). In the questionnaire, students were asked about how they found input for this part of the project. An analysis of the results indicated that only 4 out of the 13 students found input from their daily reading and viewing of English materials. All the other students tested GT's ability to translate proverbs, idioms, or culture-specific items. Before even entering these items into GT, they had expected GT's failure of providing accurate translation. It seemed that students opted for a shortcut.

This part of the data revealed that students were unsatisfied with the literal translations provided by GT and provided more refined 
Chen, C. W.-y. (2021). I participate, therefore I am: A study on students' efforts of helping Google Translate to refine its translation results. Current Trends in Teaching and Learning Translation E, 8, 449 - 482. https://doi.org/10.51287/cttle2021516

translations. However, in many instances (24.6\% of all cases), these corrections are over-corrections, even for some every-day expressions. For example, Student \#9 felt that GT's Chinese translation for "Do you have time?” as “你有時間嗎?” was incorrect; she changed it to “你有 空嗎?” which means more or less the same thing as GT's translation.

\subsection{Research Question 2: Students' Perceptions of Helping GT to Refine its Translation Output}

Generally speaking, students felt positive about helping GT to refine its translation output. In their questionnaires, many students expressed a sense of accomplishment upon finishing the GT refinement project. As Student \# 9 wrote, "I feel a sense of achievement because I think I'm not just doing homework - I'm helping people and myself at the same time." In the same light, Student \#2 remarked, “I didn't know that GT can be modified by netizens. I learned that there are many sentences and words waiting to be refined. Furthermore, due to COVID-19, many countries need to translate many materials. We can help." She felt a sense of accomplishment as she was able to contribute to the refinement effort.

During the process of finishing the GT refinement project, students also learned to detect inappropriate translation and refer to multiple sources for confirmation. Especially when the input was in English, some 
Chen, C. W.-y. (2021). I participate, therefore I am: A study on students' efforts of helping Google Translate to refine its translation results. Current Trends in Teaching and Learning Translation E, 8, 449 - 482. https://doi.org/10.51287/cttle2021516

students felt that the translation task allowed them to learn English usage they had never seen before. Translating English into Chinese also motivated some learners to think about how to write logical Chinese sentences. When the task required them to translate Chinese into English, some students mentioned that they had to check multiple sources to ensure the accuracy of their English output.

It was also found that at times, some were overwhelmed by the input they received from GT community. According to Student \#5's observation, these phrases often contained short, ungrammatical words from Google advertisements. He remarked in the questionnaire that he just had to skip them and "kept looking for reasonable sentences to translate." This remark reflects the massive volume of information circulating on the Internet on the daily basis. As there is no information provided to explain how prompts are selected by GT Community, we can only wonder why the English translation of "Weeping..." and "Hangzhou, China, May 25-26, 2017" (both from Student \#8) need verification. Also, GT Community has not explained how the tech giant Google will make use of the input netizens contribute to help to refine GT. At the time of writing (February 25, 2021), the COVID-19 section on GT Community's entrance page (https://translate.google.com/ contribute) has been removed, and some statistics can be found which show the numbers of refinement efforts (Figure 2). There is no information available for contributors to know how their contribution 
Chen, C. W.-y. (2021). I participate, therefore I am: A study on students' efforts of helping Google Translate to refine its translation results. Current Trends in Teaching and Learning Translation E, 8, 449 - 482. https://doi.org/10.51287/cttle2021516

makes a difference.

Figure 2. The numbers of "contribution" to help GT refine its Chinese/English translation (as of February 25, 2021)

\section{$1,266,400$}

所有語言的總貢獻

\section{中文 (繁體)}

\section{$1,266,400$}

總貢獻

中文 (繁體) $\rightarrow$ 英文

貢獻

ロ 驗證

文 翻譯

英文 $\rightarrow$ 中文 (繁體)

貢獻

ロっ 驗證

文
762,800

715,500

47,300

503,600

482,800

20,900

\section{DISCUSSION}


Chen, C. W.-y. (2021). I participate, therefore I am: A study on students' efforts of helping Google Translate to refine its translation results. Current Trends in Teaching and Learning Translation E, 8, 449 - 482. https://doi.org/10.51287/cttle2021516

The current study was designed to engage students in helping GT to refine its translation service. The participants were 13 freshman English majors from a university in Taiwan, and they completed a GT refinement project designed by the researcher. The results indicated that the participants were highly accurate in the various translation tasks. As explained earlier, the occasional errors stemmed from many reasons, such as students' carelessness or their inability to come up with more precise translation. Results of this study help to move the research of machine translation beyond the existing domains and applications (e.g., translation and language teaching). As students took the role of active contributors of knowledge, they developed competence in participating in the digital world. Instead of just being consumers and readers of online contents, they took the role of prosumers and writers. It was found that taking these new roles gave students a sense of achievement. From their participation, they also learned the importance of refining their language knowledge and developing their research capabilities.

Students' occasional errors in completing the first four translation tasks point to the need for them to be more careful with their translation output and to continue to develop their proficiencies in English. Some students also noticed gaps in their abilities to smoothly translate English into Chinese, especially when formal diction is required. The ease to translate between languages will not develop overnight; it will 
Chen, C. W.-y. (2021). I participate, therefore I am: A study on students' efforts of helping Google Translate to refine its translation results. Current Trends in Teaching and Learning Translation E, 8, 449 - 482. https://doi.org/10.51287/cttle2021516

definitely take some conscious effort for students to develop into highly skilled translators. For aspiring translators, the input found in GT Community offers some free practicing materials, although the tech giant does not provide contributors with any feedback on the accuracy of their contribution. If the language prompts from GT Community are used as part of a pedagogical activity, the instructor should provide feedback to students' input so that students know how they have done in the translation task.

The fifth translation task of this study yielded some interesting results. As mentioned earlier, only 4 out of the 13 students entered input from their daily reading and viewing of English materials. The majority of students purposefully entered proverbs, idioms and slang, or cultural expressions which they had anticipated some degree of GT's failure. However, this action ran counter to the original design of the study which invited students to find instances of inappropriate GT translation as they occurred in their daily reading and viewing of English materials. In other words, students were more concerned with finishing the translation task than patiently experimenting with GT's success in translating non-formulaic, daily usage. In a similar task is to be designed in future studies, clearer guidelines should be in place to avoid students taking a shortcut. A belief that their contribution matters needs to be instilled to students before they begin the refinement tasks (Jenkins, 2006). Moreover, the results also indicated that some students 
Chen, C. W.-y. (2021). I participate, therefore I am: A study on students' efforts of helping Google Translate to refine its translation results. Current Trends in Teaching and Learning Translation E, 8, 449 - 482. https://doi.org/10.51287/cttle2021516

were found to over-correct the literal translation of some GT output. In future implementation, the instructor and/or researcher can use the overcorrected instances from this study as examples to remind students how to judge acceptable translation.

The current study is limited by its sample size and time duration. To better understand how students make decisions when they try to verify the input provided by GT Community, screen-recording software such as Camtasia can be installed to record all the screen activities on students' computers. Retrospective interviews can also take place once students finish the translation tasks. Future research endeavors can also extend to other more recently developed FOMT tools such as DeepL Translator (https://www.deepl.com/translator) and encourage students to compare the output from different tools. For aspiring student translators, they can also consider join TED's Open Translation Project (https://www.ted.com/participate/translate) to help to subtitle TED talks. Such participation will further encourage students to join the participatory culture.

\section{CONCLUSION}

Guided by Jenkins' participatory culture (2006), the current study invited a group of Taiwanese EFL tertiary-level students to take the role of both consumers and prosumers to contribute translation suggestions 
Chen, C. W.-y. (2021). I participate, therefore I am: A study on students' efforts of helping Google Translate to refine its translation results. Current Trends in Teaching and Learning Translation E, 8, 449 - 482. https://doi.org/10.51287/cttle2021516

to GT. In such a culture, consumers of online contents become prosumers, and readers become writers. Through the GT refinement project implemented in this study, students were able to take the role of feedback providers to help GT refine its translation quality. It is hoped that the results of this study shed some light on the potential of engaging students in knowledge-based communities and will encourage more research endeavors on investigating the nuances of taking the role of prosumers in a participatory culture.

\section{ACKONWLEDGEMENT}

The current study was funded by Taiwan's MOE Teaching Practice Research Program (PSR1090240). I would like to thank the participants for their participation and the reviewers for their constructive comments.

\section{REFERENCES}

Briggs, N. (2018). Neural machine translation tools in the language learning classroom: Students' use, perceptions, and analysis. JALTCALL Journal, 14, 3-24. https://doi.org/10.29104/ jaltcall.v14n1.221

Case, M. (2015). Machine translation and the disruption of foreign language learning activities. eLearning Papers, 45, 4-16. 
Chen, C. W.-y. (2021). I participate, therefore I am: A study on students' efforts of helping Google Translate to refine its translation results. Current Trends in Teaching and Learning Translation E, 8, 449 - 482. https://doi.org/10.51287/cttle2021516

Chau, C. (2010). YouTube as a participatory culture. New Directions for Youth Development, 128, 65-74. https://doi.org/ 10.1002/yd. $\underline{376}$

Choi, M., Glassman, M., \& Cristol, D. (2017). What it means to be a citizen in the internet age: Development of a reliable and valid digital citizenship scale. Computers \& Education, 107, 100112. https://doi.org/ 10.1016/j.compedu.2017.01.002

Correa, M. (2014). Leaving the "peer" out of peer-editing: Online translators as a pedagogical tool in the Spanish as a second language classroom. Latin American Journal of Content and Language Integrated Learning, 7(2), 1-20. https://doi.org/ $\underline{10.5279 / 1 a c l i 1.2014 .7 .1 .1}$

Ducar, C., \& Schocket, D. H. (2018). Machine translation and the L2 classroom: Pedagogical solutions for making peace with Google translate. Foreign Language Annals, 51, 779-795. https://doi.org/10.1111/flan.12366

Enkin, E., \& Mejías-Bikandi, E. (2016). Using online translators in the second language classroom: Ideas for advanced-level Spanish. LACLIL, 9(1), 138-158. https://doi.org/10.5294/ $\underline{\text { lacli1.2016.9.1.6 }}$ 
Chen, C. W.-y. (2021). I participate, therefore I am: A study on students' efforts of helping Google Translate to refine its translation results. Current Trends in Teaching and Learning Translation E, 8, 449 - 482. https://doi.org/10.51287/cttle2021516

Garcia, I., \& Pena, M. I. (2011). Machine translation-assisted language learning: Writing for beginners. Computer Assisted Language Learning, 24, 471-487. https://doi.org/10.1080.09588221. 2011.10.1080/09588221.2011.582687

Groves, M., \& Mundt, K. (2015). Friend or foe? Google Translate in language for academic purposes. English for Specific Purposes, 37, 112-121. https://doi.org/10.1016/j.esp.2014.09. $\underline{001}$

Hutchins, J. (2001). Machine translation and human translation: In competition or in complementation? International Journal of Translation, 13, 5-20. https://doi.org/10.1108/eb026657

Jenkins, H. (2006). Fans, bloggers, and games: Exploring participatory culture. NYU Press.

Jenkins, H., Clinton, K., Purushotma, R., Robison, A. J., \& Weigel, M. (2006). Contronting the challenges of participatory culture: Media education of the $21^{\text {st }}$ century. The John D. and Catherine T. MacArthur Foundation.

Jiménez-Crespo, M. (2017). The role of translation technologies in 476 
Chen, C. W.-y. (2021). I participate, therefore I am: A study on students' efforts of helping Google Translate to refine its translation results. Current Trends in Teaching and Learning Translation E, 8, 449 - 482. https://doi.org/10.51287/cttle2021516

Spanish language teaching. Journal of Spanish Language Teaching, 4, 181-193. https://doi.org/10.1080/23247797.2017. $\underline{1408949}$

Lee, S.-M. (2019). The impact of using machine translation on EFL students' writing. Computer Assisted Language Learning, 33, 157-175. https://doi.org/10.1080/09588221.2018.1553186

Levy, P. (2000). Collective intelligence: Man's emerging world in cyberspace. Perseus.

Mundt, K., \& Groves, M. (2016). A double-edged sword: The merits and the policy implications of Google Translate in higher education. European Journal of Higher Education, 6, 387-401. https://doi.org/10.1080/21568235.2016.1172248

Niño, A. (2007). MT Post-editing: A text repair experience for the foreign language class. Cadernos de Traduçao, 1, 115 - 131. https://doi.org/10.5007/15140

Niño, A. (2009). Machine translation in foreign language learning: Language learners' and tutors' perceptions of its advantages and disadvantages. ReCALL, 21, 241-258. https://doi.org/10. $\underline{1017 / \mathrm{S} 0958344009000172}$ 
Chen, C. W.-y. (2021). I participate, therefore I am: A study on students' efforts of helping Google Translate to refine its translation results. Current Trends in Teaching and Learning Translation E, 8, 449 - 482. https://doi.org/10.51287/cttle2021516

Niño, A., Gaspari, F., \& Somers, H. (2014). The role of TESL in the age of (highly accurate) MT. Contact, 40(4), 35-42.

Somers, H., Gaspari, F., \& Niño, A. (2006). Detecting inappropriate use of free online machine translation by language students-A special case of plagiarism detection. Proceedings of the $11^{\text {th }}$ Annual Conference of the European Association for Machine Translation (pp. 41-48).

Tsai, S.-C. (2019). Using google translate in EFT drafts: A preliminary investigation. Computer Assisted Language Learning, 32, 510526. https://doi.org/10.1080/09588221.2018.1527361

Yang, Y., \& Wang, X. (2019). Modeling the intention to use machine translation for student translators: An extension of Technology Acceptance Model. Computers \& Education, 133, 116-126. https://doi.org/10.1016/j.compedu.2019.01.015

\section{APPENDIX}

Questionnaire on Helping Google Translate to Refine its Translation Results 
Chen, C. W.-y. (2021). I participate, therefore I am: A study on students' efforts of helping Google Translate to refine its translation results. Current Trends in Teaching and Learning Translation E, 8, 449 - 482. https://doi.org/10.51287/cttle2021516

Your name:

The GT refinement project contains two parts:

(1) Part I (from Chinese to English and vice versa):

(a) Contents related to COVID-19: Responding whether the translation is appropriate or providing the appropriate translation to the prompt

(b) Confirmation: Confirming whether the text is translated appropriately

(c) Translation: Providing an appropriate translation to the text

(2) Part II: Spot any inappropriate translation of GT in your daily use and report the correct translation to GT.

\section{Please try your best to answer the following questions:}

(1) For Part II of the project, how did you find texts to enter into Google Translate?

(2) What was the most difficult part of finishing this project? How did 479 
Chen, C. W.-y. (2021). I participate, therefore I am: A study on students' efforts of helping Google Translate to refine its translation results. Current Trends in Teaching and Learning Translation E, 8, 449 - 482. https://doi.org/10.51287/cttle2021516

you overcome this difficulty?

(3) What did you learn from completing this project?

(4) How did you feel upon the completion of this project? 